\title{
Study of 24 weeks antenatal visit as predictor of perinatal outcome
}

\author{
Singam S.K. ${ }^{1}$, Desai S. $^{2}$ \\ ${ }^{1}$ Dr. Sirisha kumari Singam, ${ }^{2}$ Dr. Sangeeta Desai, Associate Professor, both authors are affiliated with Department of \\ Obstetrics \& Gynaecology Dr. D.Y Patil Medical College, Kolhapur Maharashtra, India. \\ Corresponding Author: Dr. Sangeeta Desai, Associate Professor, Department of Obstetrics \& Gynaecology, Dr. D.Y \\ Patil Medical College, Kolhapur Maharashtra, India. E-mail: klpskdesai@gmail.com
}

\begin{abstract}
Introduction: Once the pregnancy progresses to 24 weeks, almost all the congenital anomalies and teratogenicity are ruled out. The progress there after is influenced by the maternal and obstetric factors. There is a need to establish the significance of all these variables with perinatal outcome and for thorough analysis. This study was focused on all low risk patients at 24 weeks of gestations to determine maternal factors affecting the perinatal outcome. Methods: The present study was a prospective observational study of 50 cases conducted in the Outpatient department of Obstetrics \& Gynecology of Padmashri Dr. D. Y Patil, Hospital and research institute, Kadamwadi, Kolhapur. The patients were advised all the regular investigations and thedata collected was analyzed to determine maternal or fetal factors affecting the perinatal outcome. Results: $82 \%$ had normal Blood pressure and 18\% patients had signs of pre-eclampsia. Factors leading to high risk pregnancy were $8 \%$ with oligohydramnios with preeclampsia with IUGR, $6 \%$ preeclampsia with IUGR, 4\% each anemia; Doppler changes with preeclampsia with IUGR, oligohydramnios respectively. Conclusion: In this study, late onset preeclampsia and anemia are the factors that are not detected at 24 weeks. It is also observed preeclampsia and anemia leads to IUGR. All the complications occurred after 36 weeks of gestational age, that means patient needs definite and regular follow up after 36 weeks.
\end{abstract}

Keywords: Preeclampsia, Oligohydramnios, IUGR, Pregnancy outcome.

\section{Introduction}

There is an increasing drive over the last 20years to push for the detection of women at risk of adverse pregnancy outcomes at 24 weeks. Once the pregnancy progresses to 24 weeks, almost all the congenital anomalies, and teratogenicities are ruled out. The progress thereafter is influenced by the maternal and obstetric factors.

There is a need to establish the significance of all these variables with perinatal outcome and Opportunity for thorough analysis and empower the lady with mode of delivery, epidural, diet, breast feeding and preparation of breasts, to know her family support structure allowing her to make informed choices regarding pregnancy and delivery [1].

A stillbirth is a baby who is born dead after 24 completed weeks of pregnancy [2]. Generally, there are various factors influencing perinatal outcome. In high

Manuscript received: $27^{\text {th }}$ December 2018

Reviewed: $4^{\text {th }}$ January 2019

Author Corrected: $10^{\text {th }}$ January 2019

Accepted for Publication: $14^{\text {th }}$ January 2019 income countries, causes like placental pathologies, infection, umbilical cord abnormalities, medical and pregnancy-specific disorders are responsible for still birth [3]. In low/middle- income countries, infections, hypertensive disorders, FGR placental insufficiency, and APH are the causes for major ante partum stillbirths [4].

Placental (uterine and umbilical artery) Doppler ultrasound study at 23-24 gestational weeks is used to measure adverse perinatal outcomes including preeclampsia, SGA newborns (smaller than $3^{\text {rd }}$ percentile), preterm delivery ( $<34$ weeks or $<37$ weeks of gestation at the time of delivery), admission to the neonatal intensive care unit and intra-uterine fetal death [4]. Preeclampsia is a major contributing cause of maternal and perinatal mortality and morbidity worldwide, especially in developing countries.

Placental (uterine and umbilical artery) Doppler ultrasound examination at 23-24 gestational weeks is the best predictor of preeclampsia [6]. 


\section{Original Research Article}

Delivery remains the only definite treatment. There is also a broad and mutual agreement to terminate the pregnancy when maternal or fetal conditions are affected or once 34 weeks of gestational age is reached. Termination at an earlier gestational age, however, is associated with an increased risk of adverse neonatal outcome [7].

Growth should be monitored from 24 weeks by measurement of the symphysiofundal height and plotting the growth by measures on a growth chart. Abnormal findings should be acted upon [8].

The leading causes of perinatal loss are preterm birth, fetal abnormalities and impaired placentation resulting to pre-eclampsia and fetal growth restriction (FGR)[9].

\section{Material and Methods}

Setting: at Padmashri Dr. D.Y Patil Hospital and Research Institute, Kolhapur in the Outpatient department of Obstetrics \& Gynecology. Type of study: prospective observational study Registration of 50 patients wasdone over a 2 years period. These women were advised all the regular investigations including uterine Doppler, glucose challenge test and specialized investigations if needed like fetal echo, and monitored for various factors which can act as predictors of perinatal outcome.

Objectives: The main objective of this study was to establish 24 week biometry as a useful adjunct in the prediction of perinatal outcome and to assess fetal factors by ultrasonography for prediction of perinatal outcome in singleton, structurally and chromosomally normal fetuses and to assess the maternal factors by routine and special investigations.At the time of registration, the baseline information was taken especially with respect to sociodemographic factors, clinical findings, and other investigations.

Inclusion Criteria: Primigravida, BMI $20-25 \mathrm{~kg} / \mathrm{m} 2$ (at viability scan), Height 150-170cms, Singleton pregnancy. Exclusion criteria: Hypertension, Endocrinal problems, multiple gestations and any medical illness complicating pregnancy. Sampling method: Patients coming to OBGY department at 24 weeks and having inclusion criteria were included in the study. Written informed consent was taken from the participants.

Pre designed questionnaire schedule consisting of standard questions related to socio demographic factors, environmental conditions, addiction among family members, family size and so on, were interviewed. In addition, questionnaire also included questions on past and present medical history, detailed obstetric examination and health seeking behavior.

Statistical method: The collected data was compiled in Microsoft Excel 2010 and analyzed using SPSS (Statistical Programme for Social Sciences) software 15 version, Open Epi Software Version 2.3.

The study findings have been discussed taking into consideration the materials, study design, and results from other relevant studies. Conclusions were drawn based on the study, and recommendations were made using the results of the present study.

\section{Results}

In this study of 50 cases, mean age was $23.86+3.00$ years, majority $52 \%$ were in age group of 21 to 25 years, followed by $36 \%$ were more than 26 years and only $12 \%$ were less than 20 years. $82 \%$ hadnormal Blood pressure and $18 \%$ patients had signs of pre-eclampsia. Late onset pre-eclampsia $(n=9) 55.55 \%$ at $38-39$ weeks, $44.44 \%$ at $37-38$ weeks. Majority $78 \%$ had vaginal delivery and only $22 \%$ had LSCS

Mean birth weight was $2.78+0.37$, majority $60 \%$ were in range of 2.6 to $3,22 \%$ in 3.1 to 3.5 and $18 \%$ in 2 to 2.5 . $18 \%$ were IUGR

Table-1: Age distribution among the study population

\begin{tabular}{|c|c|}
\hline Age & Percentage \\
\hline$<20$ & $12 \%$ \\
\hline $21-25$ & $52 \%$ \\
\hline$>26$ & $36 \%$ \\
\hline
\end{tabular}

Table shows age distribution among the study population, where it was seen that majority $52 \%$ were in age group of 21 to 25 years, followed by $36 \%$ were more than 26 years and only $12 \%$ were less than 20 years 
Table-2: Maternal outcome

\begin{tabular}{|c|c|}
\hline Maternal outcome in & Percentage \\
\hline Normal & $78 \%$ \\
\hline Anemia & $4 \%$ \\
\hline Preeclampsia & $18 \%$ \\
\hline
\end{tabular}

Table shows Maternal outcome, where $18 \%$ had preeclampsia, 4\% had anemia.

Table-3: Late onset pre-eclampsia $(n=9)$

\begin{tabular}{|c|c|}
\hline Gestational Age( in weeks) & Percentage of late onset Preeclampsia \\
\hline $37-38$ weeks & $44.44 \%$ \\
\hline $38-39$ weeks & $55.55 \%$ \\
\hline
\end{tabular}

Table shows Late onsetpre-eclampsia ( $\mathrm{n}=9$ ) 55.55\%at 38-39 weeks, 44.44\%at 37-38weeks.

Table 4: High risk factors developed afterwards.

\begin{tabular}{|c|c|}
\hline High Risk Factor & Percentage \\
\hline Anaemia & $4 \%$ \\
\hline Oligohydramnios & $4 \%$ \\
\hline Oligohydramnios with Preeclampsia with IUGR & $8 \%$ \\
\hline Preeclampsia with IUGR & $6 \%$ \\
\hline Doppler changes with Preeclampsia with IUGR & $4 \%$ \\
\hline Normal & $74 \%$ \\
\hline
\end{tabular}

Table shows High risk pregnancy shows with highest group (8\%) had oligohydramnios with preeclampsia with IUGR, and the next group having preeclampsia with IUGR (6\%) and the next group 4\% each anemia, Doppler changes with preeclampsia with IUGR, Oligohydramnios

Table 5: Mode of delivery.

\begin{tabular}{|c|c|}
\hline Mode of Delivery & Percentage \\
\hline Vaginal & $78 \%$ \\
\hline LSCS & $22 \%$ \\
\hline
\end{tabular}

Table shows mode of delivery, where majority $78 \%$ had vaginal delivery and only $22 \%$ had LSCS.

Table-6: Birth weight.

\begin{tabular}{|c|c|}
\hline Birth Weight in Kilograms & Percentage \\
\hline $2-2.5 \mathrm{~kg}$ & $18 \%$ \\
\hline $2.6-3 \mathrm{~kg}$ & $60 \%$ \\
\hline $3.1-3.5 \mathrm{~kg}$ & $22 \%$ \\
\hline
\end{tabular}

Tableshows birth weight, where it was seen that majority $60 \%$ were in range of 2.6 to $3,22 \%$ in 3.1 to 3.5 and $18 \%$ in 2 to 2.5 .

Table-7: Fetal Outcome.

\begin{tabular}{|c|c|}
\hline Fetal outcome in & Percentage \\
\hline Normal & $82 \%$ \\
\hline IUGR & $18 \%$ \\
\hline
\end{tabular}

Table shows Fetal Outcome, were it was seen that $18 \%$ newborn had IUGR. 


\section{Original Research Article}

\section{Discussion}

This study had a mean age was $23.86+3.00$ years, which is lower than those reported in studies by Young JB et al [1] who observed that mean maternal age was 29.7 or Kate b [11] who observed mean maternal age $31.9 \pm 5.4$ years. Study by R Thabane P et al [12] found that the mean age for women was $29.5 \pm 6.6$ years. Study by Praveen MA[13] found that the distribution according to age was as follows: 21-25 (46.23\%), remaining $16.12 \%, 23.65 \%, 10.75 \%, 3.23 \%$ are in the age groups of 15- $20 \mathrm{yrs}, 26-30 \mathrm{yrs}, 31-35 \mathrm{yrs},>36$ yrs, respectively.

Majority patients in this study (78\%) had vaginal delivery which is higher than several other studies i.e by Young j p et al [10] (30.3\%) had vaginal delivery and Kate B [13](25\%), Sultana et al [15] (46\%), Eshetu s et al [16] (49\%), Thabane P et al (15\%), Parveen MA [13] $(48.3 \%)$ found caesarian delivery in more number of patients. Admission scan with Doppler showed that high risk factors from neonatal aspect were seen among 20\% of patients. i.e. $8 \%$ oligohydramnios with IUGR, $4 \%$ oligohydramnios, 4\% IUGR and 4\% Doppler changes with IUGR.

High risk pregnancy, Study by Parveen m a [13] found that factors associated with pre-eclampsia in the study were anemia (55.91\%), diabetes (3.22\%), twins (4.3\%) and previous history of pre-eclampsia (7.52\%). In present study $18 \%$ had pre eclampsia which is lower than those reported in studies byKate B [11] who found that $24 \%$ had hypertension in a patient of previous preeclampsia patients.

Study by Vesna et al[14]. Observed that patients from the early-onset group had significantly higher mean blood pressure $(173.78 / 110.65 \mathrm{mmHg}$ vs. 163.72 / $104.25 \mathrm{mmHg}, \mathrm{p}<0.001)$. 1.17). In present study we have included patients of normal blood pressure in whom(18\%) patients developed late onset preeclampsia. Late onset preeclampsia is not an innocuous condition. [14] and has minimal effect over the baby. Late onset preeclampsia $(n=9)$, was $55.55 \%$ in $38-39$ weeks of gestation and $44.44 \%$ in $37-38$ weeks of gestation. In study by Kenneth et al[14], 30.7\% were seen in 34 to 43 weeks.

Many studies have shown that early onset preeclampsia is associated with low birth weight babies. Study by Kate b [11]. Observed that 31\% had preterm birth. Study Eshetu s et al [13].31\% had preterm birth. In a study by Dr Thabane p et al [10]. 5\% had IUGR.
Young $\mathrm{j} p$ et alfound that mean birth weight was 1.83 $\mathrm{kg}$, Kate b [11]. observed that mean birth weight was $2.5 \mathrm{~kg}$, Eshetu s et al [16] found $72.2 \%>2.5 \mathrm{~kg}$ and $27.8 \%<2.5 \mathrm{~kg}$. The median birth weight observed by Thabane P et al [12]was 1380 grams. Study by Vesna et al [17]. Birth weight of newborns from the early-onset group were significantly lower $(1485.75 \pm 502.15$ vs. $3229.43 \pm 592.95, \quad \mathrm{p}<0.001)$. Intrauterine growth retardation and low birth weight are responsible for lot of neonatal complications and have late sequelae in their future life.

They are common with early onset preeclampsia and needs early intervention. Study by Vesna et al [17] showed Intrauterine growth restriction (IUGR) was evident in 30 newborns from the early-onset group $(20.4 \%)$ vs. $8(11.3 \%)$ from late-onset group $(\mathrm{p}=0.027)$.

We can predict and categories patient as low risk group and high risk for the sake of neonatal complications due to IUGR and preterm babies. In the present study average neonatal weight was $2780+0.37$ gms which was in quite healthier rang. In present study it was seen that only $18 \%$ newborn had IUGR.

Study by Young JB et al [10] observed that 27.5\% had poor perinatal outcome and $72.5 \%$ had favorable outcome in patients of Doppler changes in umbilical arteryat mid trimester Single visit at 24 weeks can predict about perinatal outcome more effectively as we are ruling out all abnormalities in baby, Doppler study rules out reduced uteroplacental blood flow, glucose challenge test rules out gestational diabetes mellitus, fetal echo if necessary can detect cardiac abnormalities and early onset signs of preeclampsia can be ruled out.

We found late onset preeclampsia which has minimal impact over perinatal outcome. There was no perinatal morbidity or mortality were found in our study. Neonatal complications are associated more due to prematurity, low birth weight and IUGR babies. From the study by Parveen $\mathrm{m}$ a [13]. it was found that the most common neonatal complication was pre-maturity (23.65\%), low birth weight $(7.52 \%)$ and intra uterine growth restriction $(9.67 \%)$.

Conventional antenatal care, which involves visits every 4 weeks up to $28 \mathrm{wks}$ and every fortnightly till 36 weeks and then weekly until delivery, was established 80 years ago [18]. The high concentration of visits in the third trimester implies, as most of the complications 


\section{Original Research Article}

occur at this late stage of pregnancy and, secondly, that most adverse outcomes are unpredictable during the first or even second trimester In this study, late onset preeclampsia and anemia are the factors that are not detected at 24 weeks. It is also observed preeclampsia and anemia leads to IUGR. All the complications occurred after 36 weeks of gestational age, which determine the significance of the needs of definite and regular follow up after 36 weeks. The review by Nicolas [18] presents evidence that many pregnancy complications can now be predicted at an integrated first hospital visit at 11-13 weeks by combining data from maternal characteristics and history with findings of biophysical and biochemical tests.

\section{Conclusion}

It is therefore proposed that the traditional pyramid of care should be inverted with the main emphasis placed in the first rather than third trimester of pregnancy.

Further studies may have to be doneon large scale as differences may be attributed to the small number of patients recruited, racial differences, socioeconomic status and some certain demographic parameters such as parity, age and early age of marriage.

\section{Funding: Nil, Conflict of interest: Nil}

Permission from IRB: Yes

\section{References}

1. Cousens S, Blencowe H, Stanton C, et al. National, regional, and worldwide estimates of stillbirth rates in 2009 with trends since 1995: a systematic analysis. Lancet. 2011 Apr 16; 377(9774):1319-30. doi: 10.1016/ S0140-6736(10)62310-0.

2.Registrar General Annual Report 2014. Still birth and Infant death. Available at: http://www.nisra.gov.uk/ archive/demography/publications/annual_reports/2014/ Stillbirths.pdf. Accessed on July 2, 2015.

3. Smith GC, Fretts RC. Stillbirth. DOI:10.1016/S01406736 (07) 61723-1

4. Stillbirth in developing countries: a review of causes, risk factors and prevention strategies. J MaternFetal Neonatal Med. 2009 Mar; 22 (3):183-90. doi: 10.1080/ 14767050802559129.

5. Clausen C, Lönn L, Langhoff-Roos J. Management of placenta percreta: a review of published cases. Acta Obstet Gynecol Scand. 2014 Feb; 93 (2):138-43. doi: 10. 1111/aogs.12295. Epub 2013 Nov 25.
6. Vilar J, Say L, Gulmezoglu M. Eclampsia and preeclampsia: A worldwide health problem for 2000 years. In: Critchley H, Mac Lean A, Poston L, Walker J (Eds). Preeclampsia. London: RCOG Press; 2007.p. 189-207.

7. Sibai BM, Spinnato JA, Watson DL, et al. Pregnancy outcome in 303 cases with severe preeclampsia. Obstet Gynecol. 1984 Sep;64(3):319-25.

8. Manktelow BM, Smith LK, Evans TA, HymanTaylor P, Kurinczuk JJ, Field DJ. MBRRACE-UK Perinatal Mortality Surveillance Report UK Perinatal Death for Births from January to December 2013 Supplementary Report: UKTrusts and Health Boards.

Leicester: The Infant Mortality and Morbidity Studies Group, Department ofHealth Sciences, University of Leicester, 2015.

9. Roberge S, Nicolaides KH, Demers S, et al. Prevention of perinatal death and adverse perinatal outcome using low-dose aspirin: a meta-analysis. Ultrasound Obstet Gynecol. 2013 May;41(5):491-9. doi: 10.1002/uog.12421.

10. Byun YJ, Kim HS, Yang JI, et al. Umbilical artery Doppler study as a predictive marker of perinatal outcome in preterm small for gestational age infants. Yonsei Med J. 2009 Feb 28;50(1):39-44. doi: 10.3349 / ymj. 2009.50.1.39. Epub 2009 Feb 24.

11. Bramham K, Briley AL, Seed P, et al. Adverse maternal and perinatal outcomes in women with previous preeclampsia: a prospective study. Am J Obstet Gynecol. 2011 Jun;204(6):512.e1-9. doi: 10. 1016 /j. ajog. 2011.02.014. Epub 2011 Mar 31.

12. Thabane P. Impact of Severe Preeclampsia on Maternal and Fetal Outcomes in Preterm Deliveries. [dissertation]. Johannesberg [University of Witwatersr and], 2013, 1-106.

13. Aabidha PM, Cherian AG, Paul $E^{1}$, et al. Maternal and fetal outcome in pre-eclampsia in a secondary care hospital in South India. J Family Med Prim Care. 2015 Apr-Jun; 4(2): 257-60. doi: 10. 4103/ 2249-4863. 154669.

14. Kenneth L, Hall DR, Gebhardt S, et al. Late onset preeclampsia is not an innocuous condition. Hypertens Pregnancy. 2010; 29 (3):262-70. doi: 10.3109/10641950 902777697. 


\section{Original Research Article}

15. Sultana, Aparna J. Risk factors for pre-eclampsia and its perinatal outcome. Scholars Research Library Annals of Biological Research. 2013;4 (10):1-5.

16. Seyom E, Abera M, Tesfaye M, Fentahun N. Maternal and fetal outcome of pregnancy related hypertension in Mettu Karl Referral Hospital, Ethiopia. J Ovarian Res. 2015; 8:10, doi.10.1186/s13048-0150135-5.
17. Gasparovic VE, Beljan P, Ahmetasevic SG, Schuster S, SkrablinS. What affects the outcome of Severe preeclampsia. Signa Vitae.2015;10 (1):6-12.

18. Turning the Pyramid of Prenatal Care Kypros H. Nicolaides a, b a Harris Birthright Research Centre of Fetal Medicine, King's College Hospital, and b Department of Fetal Medicine, University College Hospital, London, UK

\section{How to cite this article?}

Singam S.K, Desai S. Study of 24 weeks antenatal visit as predictor of perinatal outcome. Obs Rev:J obstet Gynecol 2019;5(1):1-6.doi: 10.17511/joog.2019.i01.01. 